\title{
Evaluation of genetic components in traits related to superovulation, in vitro fertilization, and embryo transfer in Holstein cattle
}

\author{
K. L. Parker Gaddis,${ }^{* 1}$ S. Dikmen, ${ }^{\star} \dagger$ D. J. Null, $\ddagger$ J. B. Cole,‡ and P. J. Hansen* \\ *Department of Animal Sciences, University of Florida, Gainesville 32611 \\ †Department of Animal Science, Faculty of Veterinary Medicine, Uludag University, Bursa, 16059 Turkey \\ $\ddagger$ Animal Genomics and Improvement Laboratory, Agricultural Research Service, USDA, Beltsville, MD 20705-2350
}

\section{ABSTRACT}

The objectives of this study were to estimate variance components and identify regions of the genome associated with traits related to embryo transfer in Holsteins. Reproductive technologies are used in the dairy industry to increase the reproductive rate of superior females. A drawback of these methods remains the variability of animal responses to the procedures. If some variability can be explained genetically, selection can be used to improve animal response. Data collected from a Holstein dairy farm in Florida from 2008 to 2015 included 926 superovulation records (number of structures recovered and number of good embryos), 628 in vitro fertilization records (number of oocytes collected, number of cleaved embryos, number of high- and low-quality embryos, and number of transferrable embryos), and 12,089 embryo transfer records (pregnancy success). Two methods of transformation (logarithmic and Anscombe) were applied to count variables and results were compared. Univariate animal models were fitted for each trait with the exception of pregnancy success after embryo transfer. Due to the binary nature of the latter trait, a threshold liability model was fitted that accounted for the genetic effect of both the recipient and the embryo. Both transformation methods produced similar results. Single-step genomic BLUP analyses were performed and SNP effects estimated for traits with a significant genetic component. Heritability of number of structures recovered and number of good embryos when log-transformed were $0.27 \pm 0.08$ and $0.15 \pm 0.07$, respectively. Heritability estimates from the in vitro fertilization data ranged from $0.01 \pm 0.08$ to $0.21 \pm 0.15$, but were not significantly different from zero. Recipient and embryo heritability (standard deviation) of pregnancy success after embryo transfer was $0.03(0.01)$ and $0.02(0.01)$, respectively. The 10-SNP

Received August 23, 2016.

Accepted November 21, 2016.

${ }^{1}$ Corresponding author: kristen.gaddis@cdcb.us window explaining the largest proportion of variance $(0.37 \%)$ for total structures collected was located on chromosome 8 beginning at 55,663,248 bp. Similar regions were identified for number of good embryos, with the largest proportion of variance $(0.43 \%)$ explained by a 10-SNP window on chromosome 14 beginning at $26,713,734 \mathrm{bp}$. Results indicate that there is a genetic component for some traits related to superovulation and that selection should be possible. Moreover, the genetic component for superovulation traits involves some genomic regions that are similar to those for other fertility traits currently evaluated.

Key words: embryo transfer, genetic parameter, in vitro fertilization, superovulation

\section{INTRODUCTION}

The widespread adoption of AI using frozen semen has allowed bulls of superior genetic merit to produce many more offspring than was possible using natural service. However, female reproductive rates have generally remained limited by the number of pregnancies a cow can carry to term during her life. Introduction of embryo technologies began several decades ago, with the development of protocols for superovulation and embryo transfer (ET) beginning in the late 1940s (Hasler, 2014). Reproductive technologies, including superovulation, in vitro fertilization (IVF), and ET, allow for higher rates of genetic improvement to be achieved by increasing the reproduction of superior females (Tonhati et al., 1999). Studies conducted in the 1980s and 1990s indicated that reproductive technologies could increase genetic gain by 10 to $20 \%$ compared with traditional breeding schemes (e.g., Nicholas and Smith, 1983; Colleau, 1991; Ruane and Thompson, 1991).

Opportunities remain to combine reproductive technologies with selective breeding programs to increase genetic gain (Loi et al., 2016). Improvements in sequencing technologies over the past decade have allowed for dense panels of molecular markers to be 
produced in a cost-effective manner. Single nucleotide polymorphisms are the most commonly used markers for genotyping. Genomic selection methods have been widely investigated and implemented in livestock species due to this increased availability of dense SNP marker panels. In addition to being used to predict genomic values for quantitative traits (Meuwissen et al., 2001), SNP can also be used to identify regions of the genome associated with a trait of interest. Thomasen et al. (2016) concluded that using reproductive technologies in combination with genomic selection methods can increase the annual rate of genetic gain in dairy breeding programs, which may result in greater farm profitability. Limiting factors of reproductive technologies continue to be high cost as well as variability of animal response to procedures (Jaton et al., 2016). Despite this, in 2014 the bovine ET industry reported 614,464 in vitro-derived embryos collected and 464,582 in vitro-derived embryos transferred throughout the world (Perry, 2015).

If these traits have a genetic component, a producer may select animals that respond well to these procedures. Moreover, it is possible that some of the genes controlling response to embryo technologies are also involved in determining reproductive function in females subjected to natural or artificial insemination. Previous research conducted with Holstein-Friesian cows in Brazil estimated the heritability of number of transferable embryos in a superovulation program as 0.03 with the repeatability equal to 0.13 (Tonhati et al., 1999). These estimates are low compared with production traits such as milk yield, which has a heritability of approximately 0.20 (VanRaden and Cole, 2014) and repeatability of 0.55 (Council on Dairy Cattle Breeding, 2014). When studying results from an IVF program, Machado et al. (2006) found significantly less variation in ovum pick-up response and in vitro embryo production among monozygotic twins compared with unrelated animals, indicating that the traits may have a genetic component. In support of these results, a later study estimated genetic components for several traits related to IVF including number of cumulus-oocyte complexes, quality of cumulus-oocyte complexes, number and proportion of cleaved embryos at d 4, and number and proportion of total and transferable embryos at $\mathrm{d} 7$ of culture (Merton et al., 2009). Significant genetic components were estimated for number of cumulus-oocyte complexes as well as for both total and transferable embryos at d 7 of culture (Merton et al., 2009). Heritabilities accounting for covariance between donor, sire, and recipient in superovulation procedures have also been estimated for traits such as number of flushed ova and number of transferable ova (König et al., 2007). Most recently, significant heritability estimates for total number of embryos and number of viable embryos from superovulation have been reported for the Canadian Holstein population (Jaton et al., 2016). In this population, heritability of total number of embryos was $0.15 \pm$ 0.01 and $0.17 \pm 0.01$ using a logarithmic or Anscombe transformation, respectively. Heritability for number of viable embryos was $0.14 \pm 0.01$ in the study regardless of transformation method.

The objectives of this research were to estimate genetic parameters for traits related to embryo production technologies, including pregnancy success after ET. For traits with a significant $(P<0.05)$ genetic component, genome-wide association analyses were conducted and genomic regions of interest were further investigated to identify genes that may explain the effects observed.

\section{MATERIALS AND METHODS}

\section{Data}

Data were collected from a registered Holstein dairy operation located in Bell, Florida $\left(29.75^{\circ} \mathrm{N}, 82.86^{\circ} \mathrm{W}\right)$ from 2008 through 2015. Lactating cows were housed in either free-stall barns equipped with fans, sprinklers, and misters or in tunnel ventilation barns. Cows were milked 3 times per day. Selected females (cows and heifers) were used to produce embryos either in vivo by superovulation with FSH or by IVF of oocytes harvested from FSH treated cows using transvaginal, ultrasoundguided follicular aspiration. Production of embryos by IVF was performed by the laboratory of TransOva in Boonsboro, Maryland. In vitro fertilization donors were typically transported to the Transova facility in Maryland for embryo production and embryos were then shipped to the farm for transfer. Both conventional and sexed semen were employed for superovulation, and conventional and reverse-sorted semen were used for IVF. Reverse-sorted semen allows sexed sperm to be obtained from samples that have been previously frozen (Morotti et al., 2014). Embryos produced by superovulation and IVF were transferred to recipient females. Both heifers and cows were used as recipients. Few animals $(\mathrm{n}=45)$ overlapped between the superovulation and IVF data sets. For ET, embryos were transferred either fresh (i.e., without cryopreservation) or after conventional slow freezing with ethylene glycol. Additional details of the ET protocols can be found in Ferraz et al. (2016).

Superovulation data collected $(\mathrm{n}=926)$ included total number of structures recovered (i.e., total number of unfertilized oocytes and embryos) and total number of good embryos [grade 1 embryos using the grading system described by Robertson and Nelson (1998)]. Proportion of good embryos was also calculated as the 
total number of good embryos divided by the total number of structures recovered. Flushing dates ranged from 2008 through 2015 . In vitro fertilization data $(\mathrm{n}=628)$ were collected from 2013 to 2015 and included number of oocytes recovered, number of cleaved embryos, number of high- and low-quality embryos, and number of transferrable embryos. Embryo quality grades range from 1 to 4 , where 1 is good or excellent, 2 is fair, 3 is poor, and 4 is dead or degenerating (Robertson and Nelson, 1998). An embryo was classified as high quality if it was a grade 1 (Robertson and Nelson, 1998) and as low quality if the grade was less than 1. Embryo development stage ranged from values of 3 to 9 . An early morula was given a score of 3 , a compact morula was given a score of 4 , an early blastocyst was given a score of 5 , a blastocyst was given a score of 6 , an expanded blastocyst was given a score of 7 , a hatching blastocyst was given a score of 8 , and a hatched blastocyst was given a score of 9 (Robertson and Nelson, 1998). An embryo was considered transferrable if it was a morula or blastocyst and was not classified as degenerate. Proportion of high-quality embryos was calculated as the number of high-quality embryos divided by the number of cleaved embryos. This variable was used to provide an indication of the donor's genetic effect on the embryo's competence to develop regardless of how many oocytes were harvested. Pregnancy success after ET was based on whether a recipient was diagnosed as pregnant following transfer $(\mathrm{n}=12,089)$. Pregnancy diagnosis was by rectal palpation of the reproductive tract at approximately $41 \mathrm{~d}$ of gestation. Data were collected from 2011 through 2015 including additional variables such as embryo type, quality of embryo, stage of embryo development, and technician.

Distributions of the variables of interest were investigated for normality. Count variables (e.g., total number of structures recovered, number of oocytes recovered, and so on) from the superovulation and IVF data sets were transformed using 2 different methods: logarithmic transformation and Anscombe transformation. A logarithmic transformation is commonly used to produce approximately normal response variables from discrete variables (Finney, 1948). The transformation applied was

$$
y=\ln (x+1),
$$

where $y$ represents the transformed variable and $x$ represents the original variable of interest. The Anscombe transformation was introduced in 1948 to normalize data following Poisson, binomial, or negative-binomial distributions (Anscombe, 1948). The Anscombe transformation applied was

$$
y=2 \times \sqrt{\left(x+\frac{3}{8}\right)},
$$

with $y$ again representing the transformed variable of interest and $x$ representing the untransformed variable. Variables that were transformed using the above formulas included total structures recovered and number of good embryos from the superovulation data set, as well as total structures recovered, number of cleaved embryos, number of high quality embryos, number of low-quality embryos, and number of transferrable embryos from the IVF data set. Variables represented as a proportion (proportion of good embryos in the superovulation data set and proportion of high-quality embryos in the IVF data set) were transformed using an arc-sine transformation (Sokal and Rohlf, 1995). Pregnancy success in the ET data set was classified as a binary variable (pregnancy or no pregnancy after one ET) and was thus analyzed using a threshold model.

An animal pedigree was trimmed to include 3 generations resulting in the inclusion of 2,208 animals for the superovulation data set. When very deep pedigrees are used with limited numbers of phenotypes, it can be difficult to obtain convergence when estimating variance components (Lourenco et al., 2014; Yang and Su, 2016). The pedigree for the IVF data set included 560 animals. The pedigree for the ET data set consisted of 33,020 animals. Genotypes were available for 658 animals in the superovulation data set and all animals $(\mathrm{n}=129)$ in the IVF data set. Animals were genotyped using different marker panels; however, all genotypes were imputed to include those markers used for official December 2015 US genomic evaluations $(\mathrm{n}=60,671$ ). These SNP have been previously selected based on criteria such as minor allele frequency, parent-progeny conflicts, and call rate (Wiggans et al., 2014).

\section{Models}

Univariate repeatability animal models were fitted for each of the variables of interest from the superovulation and IVF data sets using AIREMLF90 version 1.116 (Misztal et al., 2002). The model fitted for total number of structures recovered, number of good embryos, and proportion of good embryos from the superovulation data set is given below:

$$
y=\mathbf{X} \boldsymbol{\beta}+\mathbf{Z}_{\mathbf{a}} a+\mathbf{Z}_{\mathbf{p e}} p e+\varepsilon,
$$

where $\boldsymbol{\beta}$ represents a vector of fixed effects including year-season of superovulation and covariate of donor's age at superovulation; $\mathbf{X}$ is the corresponding incidence 
matrix; $a$ represents the random donor effect where $a \sim N\left(0, \mathbf{A} \sigma_{a}^{2}\right)$, where $\sigma_{a}^{2}$ represents the additive genetic variance and $\mathbf{A}$ represents the numerator relationship matrix; pe represents a random permanent environment effect; $\mathbf{Z}_{\mathrm{a}}$ and $\mathbf{Z}_{\mathrm{pe}}$ represent the respective incidence matrices; and $\varepsilon$ represents the random residual, where $\varepsilon \sim N\left(0, \mathbf{I} \sigma_{\varepsilon}^{2}\right)$, where $\mathbf{I}$ represents an identity matrix and $\sigma_{\varepsilon}^{2}$ represents the residual variance. Season was classified into 4 categories by month: winter (December, January, February), spring (March, April, May), summer (June, July, August), and fall (September, October, November). Age at superovulation was calculated based on the date of superovulation and birthdate from pedigree information. Least squares means with respect to the effect of season were calculated for total structures recovered and number of good embryos without transformation using the GLM procedure of SAS (version 9.4, SAS Institute Inc., Cary, NC).

A bivariate repeatability animal model was also used to estimate the genetic correlation between total number of structures recovered and number of good embryos in the superovulation data set. Fixed effects and covariates remained the same as those listed above. Random effects were assumed to be normally distributed with mean 0 and the following (co)variance structure:

$$
\operatorname{var}\left[\begin{array}{c}
t_{1} \\
t_{2} \\
p e_{1} \\
p e_{2} \\
\varepsilon_{1} \\
\varepsilon_{2}
\end{array}\right]=\left[\begin{array}{cccccc}
\sigma_{t_{1}}^{2} \mathbf{A} & \sigma_{t_{1} t_{2}} \mathbf{A} & 0 & 0 & 0 & 0 \\
\sigma_{t_{2} t_{1}} \mathbf{A} & \sigma_{t_{2}}^{2} \mathbf{A} & 0 & 0 & 0 & 0 \\
0 & 0 & \sigma_{p e_{1}}^{2} & \sigma_{p e_{1} p e_{2}} & 0 & 0 \\
0 & 0 & \sigma_{p e_{2} p e_{1}} & \sigma_{p e_{2}}^{2} & 0 & 0 \\
0 & 0 & 0 & 0 & \sigma_{\varepsilon_{1}}^{2} & \sigma_{\varepsilon_{1} \varepsilon_{2}} \\
0 & 0 & 0 & 0 & \sigma_{\varepsilon_{2} \varepsilon_{1}} & \sigma_{\varepsilon_{2}}^{2}
\end{array}\right] \text {, }
$$

where $\sigma_{t_{1}}^{2}=$ additive genetic variance for trait $1, \sigma_{t_{2}}^{2}=$ additive genetic variance for trait $2, \sigma_{t_{1} t_{2}}$ and $\sigma_{t_{2} t_{1}}=$ additive genetic covariance between traits 1 and 2 , and A represents the numerator relationship matrix. This notation follows for the (co)variance of permanent environmental effects $(p e)$ and residual effects $(\varepsilon)$.

Heritability of the donor's genetic effect on each trait was calculated as

$$
h_{d}^{2}=\sigma_{d}^{2} /\left(\sigma_{d}^{2}+\sigma_{p e}^{2}+\sigma_{\varepsilon}^{2}\right),
$$

where $\sigma_{d}^{2}$ represents donor additive genetic variance, $\sigma_{p e}^{2}$ represents variance of donor permanent environmental effect, and $\sigma_{\varepsilon}^{2}$ represents residual variance. Repeatability was calculated as

$$
r_{d}=\left(\sigma_{d}^{2}+\sigma_{p e}^{2}\right) /\left(\sigma_{d}^{2}+\sigma_{p e}^{2}+\sigma_{\varepsilon}^{2}\right) .
$$

Approximate standard errors of heritability, repeatability, and genetic correlation (in the case of the bivariate model) were computed from the inverse average information matrix (Klei and Tsuruta, 2008). Approximate standard error (SE) of heritability was calculated as follows:

$$
\begin{aligned}
& S E_{h^{2}}^{2}=\left[\begin{array}{ccc}
\frac{h^{2}\left(1-h^{2}\right)}{\sigma_{a}^{2}} & \frac{-h^{2}\left(h^{2}\right)}{\sigma_{a}^{2}} & \left.\frac{-h^{2}\left(h^{2}\right)}{\sigma_{a}^{2}}\right]
\end{array}\right] \\
& \times\left[\begin{array}{ccc}
\operatorname{var}\left(\sigma_{a}^{2}\right) & \operatorname{cov}\left(\sigma_{a}^{2}, \sigma_{p e}^{2}\right) & \operatorname{cov}\left(\sigma_{a}^{2}, \sigma_{\varepsilon}^{2}\right) \\
\operatorname{cov}\left(\sigma_{p e}^{2}, \sigma_{a}^{2}\right) & \operatorname{var}\left(\sigma_{p e}^{2}\right) & \operatorname{cov}\left(\sigma_{p e}^{2}, \sigma_{\varepsilon}^{2}\right) \\
\operatorname{cov}\left(\sigma_{\varepsilon}^{2}, \sigma_{a}^{2}\right) & \operatorname{cov}\left(\sigma_{\varepsilon}^{2}, \sigma_{p e}^{2}\right) & \operatorname{var}\left(\sigma_{\varepsilon}^{2}\right)
\end{array}\right] \times\left[\begin{array}{l}
\frac{h^{2}\left(1-h^{2}\right)}{\sigma_{a}^{2}} \\
\frac{-h^{2}\left(h^{2}\right)}{\sigma_{a}^{2}} \\
\frac{-h^{2}\left(h^{2}\right)}{\sigma_{a}^{2}}
\end{array}\right],
\end{aligned}
$$

where the variables are as defined previously. The preceding row vector and latter column vector are the partial derivatives of $h^{2}$ with respect to $a$, pe, and $\varepsilon$, respectively. Values for the 3 by 3 matrix were taken from the inverse average information matrix provided in the output of AIREMLF90. Approximate standard error of repeatability was calculated similarly, taking the partial derivatives of repeatability with respect to $\sigma_{a}^{2}, \sigma_{p e}^{2}$, and $\sigma_{\varepsilon}^{2}$, respectively. Approximate standard error of the genetic correlation in the bivariate analysis was calculated as follows:

$$
\begin{aligned}
& S E_{r}^{2}=\left[\begin{array}{lll}
\frac{-r}{2 x_{1}} & \frac{-r}{2 x_{2}} & \frac{r}{x_{12}}
\end{array}\right] \\
& \times\left[\begin{array}{ccc}
\operatorname{var}\left(x_{1}\right) & \operatorname{cov}\left(x_{1}, x_{2}\right) & \operatorname{cov}\left(x_{1}, x_{12}\right) \\
\operatorname{cov}\left(x_{2}, x_{1}\right) & \operatorname{var}\left(x_{2}\right) & \operatorname{cov}\left(x_{2}, x_{12}\right) \\
\operatorname{cov}\left(x_{12}, x_{1}\right) & \operatorname{cov}\left(x_{12}, x_{2}\right) & \operatorname{var}\left(x_{12}\right)
\end{array}\right] \times\left[\begin{array}{c}
\frac{-r}{2 x_{1}} \\
\frac{-r}{2 x_{2}} \\
\frac{r}{x_{12}}
\end{array}\right],
\end{aligned}
$$

where $r$ represents the correlation, $x_{1}$ represents the estimate of genetic variance for trait $1, x_{2}$ represents the estimate of genetic variance for trait 2 , and $x_{12}$ represents the estimate of genetic covariance between traits 1 and 2. The preceding row vector and following column vector are composed of partial derivatives 
of genetic correlation with respect to $x_{1}, x_{2}$, and $x_{12}$, respectively.

The following model was used in AIREMLF90 version 1.116 (Misztal et al., 2002) for variables of interest from the IVF data set:

$$
y=\mathbf{X} \boldsymbol{\beta}+\mathbf{Z}_{\mathbf{a}} a+\mathbf{Z}_{\mathbf{p e}} p e+\varepsilon,
$$

where $\boldsymbol{\beta}$ represents a vector of fixed effects including year-season of aspiration, semen type, and a covariate of donor's age at aspiration. Semen type included 3 levels: conventional, reverse-sorted female, and sorted frozen semen. The remaining variables were the same as described above for the superovulation data set. Heritability and repeatability, as well as their respective standard errors, were calculated as described above. Least squares means for each trait with respect to season and semen type were calculated on untransformed data using the GLM procedure of SAS (version 9.4, SAS Institute Inc., Cary, NC).

Pregnancy success was analyzed with THRGIBBS1F90 version 2.108 (Tsuruta and Misztal, 2006) to account for the binary nature of the trait. A total of 500,000 iterations were completed with the first 50,000 discarded as burn-in, saving every 100 samples. Model specification is shown below:

$$
y=\mathbf{X} \boldsymbol{\beta}+\mathbf{Z}_{\mathbf{r}} r+\mathbf{Z}_{\mathbf{p e}} p e+\mathbf{Z}_{\mathbf{e}} e+\varepsilon,
$$

where $\boldsymbol{\beta}$ represents a vector of fixed effects including year-season of transfer, embryo type, stage of embryo, quality of embryo, and technician; $r$ represents a random effect of recipient; pe represents the permanent environment effect of the recipient; $e$ represents the random effect of the embryo; and $\varepsilon$ represents the residual. Random effects were assumed to follow a normal distribution with mean zero and the following (co) variance structure:

$$
\operatorname{var}\left[\begin{array}{c}
e \\
r \\
p e \\
\varepsilon
\end{array}\right]=\left[\begin{array}{cccc}
\sigma_{e}^{2} \mathbf{A} & \sigma_{e, r} \mathbf{A} & 0 & 0 \\
\sigma_{e, r} \mathbf{A} & \sigma_{r}^{2} \mathbf{A} & 0 & 0 \\
0 & 0 & \mathbf{I} \sigma_{p e}^{2} & 0 \\
0 & 0 & 0 & \mathbf{I}
\end{array}\right],
$$

in which $\sigma_{e}^{2}$ represents the additive genetic variance of the embryo, $\sigma_{r}^{2}$ represents the additive genetic variance of the recipient effect, $\sigma_{e, r}$ represents the additive genetic covariance between embryo and recipient, A represents the additive relationship matrix, $\sigma_{p e}^{2}$ represents the variance of the permanent environment effect of the recipient, and $\mathbf{I}$ indicates an identity matrix. The residual was fixed at 1 for identifiability. Post-Gibbs analyses were completed using the POSTGIBBSF90 program (version 3.02; Misztal et al., 2002). Trace plots were inspected to ensure that convergence had been reached. Heritability of the recipient was calculated as

$$
h_{r}^{2}=\sigma_{r}^{2} /\left(\sigma_{r}^{2}+2 \sigma_{r, e}+\sigma_{e}^{2}+\sigma_{p e}^{2}+\sigma_{\varepsilon}^{2}\right) .
$$

Similarly, heritability of the embryo was calculated as

$$
h_{e}^{2}=\sigma_{e}^{2} /\left(\sigma_{r}^{2}+2 \sigma_{r, e}+\sigma_{e}^{2}+\sigma_{p e}^{2}+\sigma_{\varepsilon}^{2}\right) .
$$

Repeatability of the recipient was calculated as

$$
r_{r}=\left(\sigma_{r}^{2}+\sigma_{p e}^{2}\right) /\left(\sigma_{r}^{2}+2 \sigma_{r, e}+\sigma_{e}^{2}+\sigma_{p e}^{2}+\sigma_{\varepsilon}^{2}\right) .
$$

Posterior standard deviations were calculated for each estimate.

Effect of the embryo accounted for effects of both the sire and donor dam to produce a viable embryo, similar to the simplified model presented by König et al. (2007). The pedigree for this analysis was extended to include the embryo, sire, and donor dam. Analyses were also attempted in which effects of sire and donor were separated, but those models did not converge. Levels of embryo type included superovulation-fresh, superovulation-frozen, IVF-fresh, and IVF-frozen. Stage of embryo development ranged from 3 to 9 and was based on those described by the International Embryo Transfer Society (Robertson and Nelson, 1998). Levels of embryo quality ranged from 1 to 3 and were also based on those described by the International Embryo Technology Society (Robertson and Nelson, 1998). There were 10 levels of technician effect. Mean pregnancy rate with respect to fixed effects were calculated using the MEANS procedure of SAS (version 9.4, SAS Institute Inc., Cary, NC).

For traits where a significant genetic component was estimated (number of structures recovered and number of good embryos from the superovulation data set), single-step genomic BLUP analyses were conducted using AIREMLF90 version 1.116 with genomic options. In these analyses, the additive relationship matrix (A) was replaced by a blended $\mathbf{H}$ matrix that incorporated both pedigree and genomic information, the inverse of which is shown below (Aguilar et al., 2011):

$$
\mathbf{H}^{-1}=\mathbf{A}^{-1}+\left[\begin{array}{cc}
\mathbf{0} & \mathbf{0} \\
\mathbf{0} & \alpha \mathbf{G}^{-1}-\beta \mathbf{A}_{22}^{-1}
\end{array}\right],
$$


where $\mathbf{A}_{22}^{-1}$ represents the inverse additive relationship matrix between genotyped individuals, $\mathbf{G}^{-1}$ represents the inverse genomic relationship matrix between genotyped individuals, $\alpha$ was equal to 0.95 , and $\beta$ was equal to 0.05 (the default parameterization in preGSf90). The $\mathbf{H}$ matrix was incorporated into the models described above for each trait. The postGSf90 (version 1.35) was used to calculate SNP effects and 10-SNP window variances (Aguilar et al., 2014). Windows explaining the largest proportions of variance were investigated for putative genes using BovineMine (Elsik et al., 2016). Results were compared with previous results from studies of similar traits (e.g., number of transferrable embryos, early embryonic survival, ovulation rate) using CattleQTLdb (Hu et al., 2013).

\section{RESULTS AND DISCUSSION}

\section{Superovulation Data Set}

Summary statistics of the untransformed data can be found in Table 1. The total number of structures recovered ranged from 0 to 51 , with an average per superovulation of $7.6(\mathrm{SD}=6.6)$. The number of good embryos collected ranged from 0 to 26 , and averaged $5.2(\mathrm{SD}=4.8)$ per superovulation. Least squares means of total structures recovered with respect to season were equal to $9.23 \pm 0.41$ for winter, $8.07 \pm 0.45$ for spring, $7.00 \pm 0.57$ for summer, and $7.64 \pm 0.51$ for fall. Values were not significantly different $(P<0.05)$ across seasons. A similar pattern was found for number of good embryos.
Pedigree-based estimates of variance components are included in Table 2 for total structures recovered and number of good embryos. No significant difference was found in heritability estimates between the 2 transformation methods. Heritability for total number of structures recovered was $0.27 \pm 0.08$, regardless of transformation and repeatability was $0.40 \pm 0.02$ and $0.42 \pm 0.06$ for log- and Anscombe-transformed data, respectively. These estimates were higher than those found for number of good embryos. Heritability estimates calculated herein were comparable to previous reports. König et al. (2007) estimated donor heritability equal to $0.231 \pm 0.091$ for number of flushed ova using Holstein cows from 4 regions of northwest Germany from 1998 to 2004. These estimates are all higher than an earlier heritability estimate for number of transferrable embryos of 0.03 (Tonhati et al., 1999).

Heritability of total number of good embryos ranged from $0.15 \pm 0.07$ to $0.16 \pm 0.07$, with log and Anscombe transformations, respectively. Conversely, heritability for proportion of good embryos was extremely small (5.25E-6), indicating little to no additive genetic effect of the donor on the embryo's competence to develop irrespective of how many ovulations took place. Heritability for number of good embryos estimated were comparable to those for number of viable embryos reported by Jaton et al. (2016). Repeatability for number of good embryos $(0.27 \pm 0.02$ and $0.29 \pm 0.05$ with $\log$ and Anscombe transformations, respectively) was lower than that reported by Eriksson et al. (2007) in Swedish Red Cattle and Swedish Holstein heifers (0.44 and 0.40 for number of collected embryos and number

Table 1. Summary statistics including total, average per procedure, SD, minimum, and maximum of untransformed data for superovulation, in vitro fertilization, and embryo transfer data sets

\begin{tabular}{|c|c|c|c|c|c|}
\hline Item & Total & Average & SD & Minimum & Maximum \\
\hline Number of records & 926 & - & - & - & - \\
\hline Number of donors & 723 & - & - & - & - \\
\hline Total good embryos & 4,617 & 5.11 & 4.84 & 0 & 26 \\
\hline \multicolumn{6}{|l|}{ In vitro fertilization data set } \\
\hline Number of records & 628 & - & - & - & - \\
\hline Number of cleaved embryos & 9,927 & 15.81 & 8.35 & 0 & 55 \\
\hline Number of high-quality embryos & 1,453 & 2.34 & 2.51 & 0 & 14 \\
\hline Number of low-quality embryos & 3,166 & 5.09 & 3.53 & 0 & 19 \\
\hline Number of transferrable embryos & 3,451 & 5.59 & 4.37 & 0 & 24 \\
\hline \multicolumn{6}{|l|}{ Embryo transfer data set } \\
\hline Number of records & 12,089 & - & - & - & - \\
\hline Number of donors & 610 & - & - & - & - \\
\hline
\end{tabular}


Table 2. Pedigree-based estimates of variance components \pm SE for superovulation data set including total structures recovered and number of good embryos

\begin{tabular}{|c|c|c|c|c|}
\hline \multirow[b]{2}{*}{ Item } & \multicolumn{2}{|c|}{ Total structures } & \multicolumn{2}{|c|}{ Good embryos } \\
\hline & Logarithmic & Anscombe & Logarithmic & Anscombe \\
\hline Permanent environment & $0.101 \pm 0.065$ & $0.798 \pm 0.434$ & $0.095 \pm 0.065$ & $0.549 \pm 0.353$ \\
\hline Residual & $0.478 \pm 0.047$ & $3.11 \pm 0.309$ & $0.562 \pm 0.054$ & $2.98 \pm 0.294$ \\
\hline Heritability & $0.273 \pm 0.077$ & $0.272 \pm 0.076$ & $0.148 \pm 0.065$ & $0.160 \pm 0.065$ \\
\hline Repeatability & $0.399 \pm 0.024$ & $0.421 \pm 0.061$ & $0.271 \pm 0.019$ & $0.290 \pm 0.046$ \\
\hline
\end{tabular}

of transferrable embryos, respectively), but was more comparable to that reported by Jaton et al. (2016) for number of viable embryos equal to 0.24 with an Anscombe transformation.

Genetic correlation between total structures recovered and number of good embryos estimated from the bivariate analysis was $1.00 \pm 0.04$ and $1.00 \pm 0.03$ for logarithmic and Anscombe transformations, respectively. High correlations were expected because number of good embryos is a subset of total number of structures recovered and the phenotypic correlation between the traits was high (0.84). High genetic correlation (0.70 \pm 0.28 ) has previously been estimated between number of collected embryos and number of transferrable embryos (Eriksson et al., 2007). It must be noted that the trait number of collected embryos analyzed by Eriksson et al. (2007) did not include oocytes, whereas both oocytes and embryos collected are included in our trait total structures recovered. In all analyses, total structures recovered had higher donor variance, resulting in higher heritability compared with number of good embryos. Given the high correlation between the 2 traits, genetic selection for total structures recovered will also result in a corresponding correlated response of selection for number of good embryos.

\section{Genomic Analyses}

Variance component estimates from genomic analyses of total structures recovered and number of good embryos from the superovulation data set are included in Table 3. Estimates using the blended $\mathbf{H}$ matrix were comparable to those obtained using the additive relationship matrix A. Heritability and repeatability increased with genomic data, but not significantly $(P$ $<0.05)$ so. Heritability of total structures recovered in the ssGBLUP analysis was $0.31 \pm 0.067$ and $0.32 \pm$ 0.067 with logarithmic and Anscombe transformations, respectively. Heritability of number of good embryos in the ssGBLUP analysis was $0.21 \pm 0.063$ and $0.22 \pm$ 0.063 with logarithmic and Anscombe transformations, respectively.

Regions of the genome associated with total structures recovered and number of good embryos were investigated and compared across transformation methods. Chromosomes with the largest SNP effects for total structures recovered (log-transformed) included BTA3 (3,552,001 bp), BTA8 (21,284,778 bp), BTA11 $(89,371,911$ bp $), \quad$ BTA19 $(58,188,793$ bp $), \quad$ BTA27 $(38,964,379 \mathrm{bp})$, and BTA28 $(3,785,867 \mathrm{bp})$. The largest effect was located on BTA19 (Supplemental Figure S1; https://doi.org/10.3168/jds.2016-11907). The region explaining the largest proportion of variance for total structures recovered in the superovulation data was located on BTA8 beginning at 55,663,248 bp. Additional peaks indicating large proportions of variance explained were located on chromosomes $5,13,14$, and 21 (Figure 1).

In general, results were similar across the 2 data transformations, though some re-ranking of the top SNP did occur. In most cases, SNP with large effect were identified regardless of transformation method.

Table 3. Genomic estimates of variance components \pm SE for superovulation data set including total structures recovered and number of good embryos

\begin{tabular}{|c|c|c|c|c|}
\hline \multirow[b]{2}{*}{ Item } & \multicolumn{2}{|c|}{ Total structures } & \multicolumn{2}{|c|}{ Good embryos } \\
\hline & Logarithmic & Anscombe & Logarithmic & Anscombe \\
\hline Donor & $0.251 \pm 0.061$ & $1.749 \pm 0.420$ & $0.163 \pm 0.053$ & $0.924 \pm 0.289$ \\
\hline Permanent environment & $0.078 \pm 0.058$ & $0.598 \pm 0.387$ & $0.056 \pm 0.061$ & $0.343 \pm 0.330$ \\
\hline Residual & $0.471 \pm 0.046$ & $3.068 \pm 0.302$ & $0.558 \pm 0.054$ & $2.964 \pm 0.290$ \\
\hline Heritability & $0.314 \pm 0.067$ & $0.323 \pm 0.067$ & $0.21 \pm 0.063$ & $0.22 \pm 0.063$ \\
\hline Repeatability & $0.411 \pm 0.025$ & $0.433 \pm 0.064$ & $0.282 \pm 0.022$ & $0.299 \pm 0.053$ \\
\hline
\end{tabular}




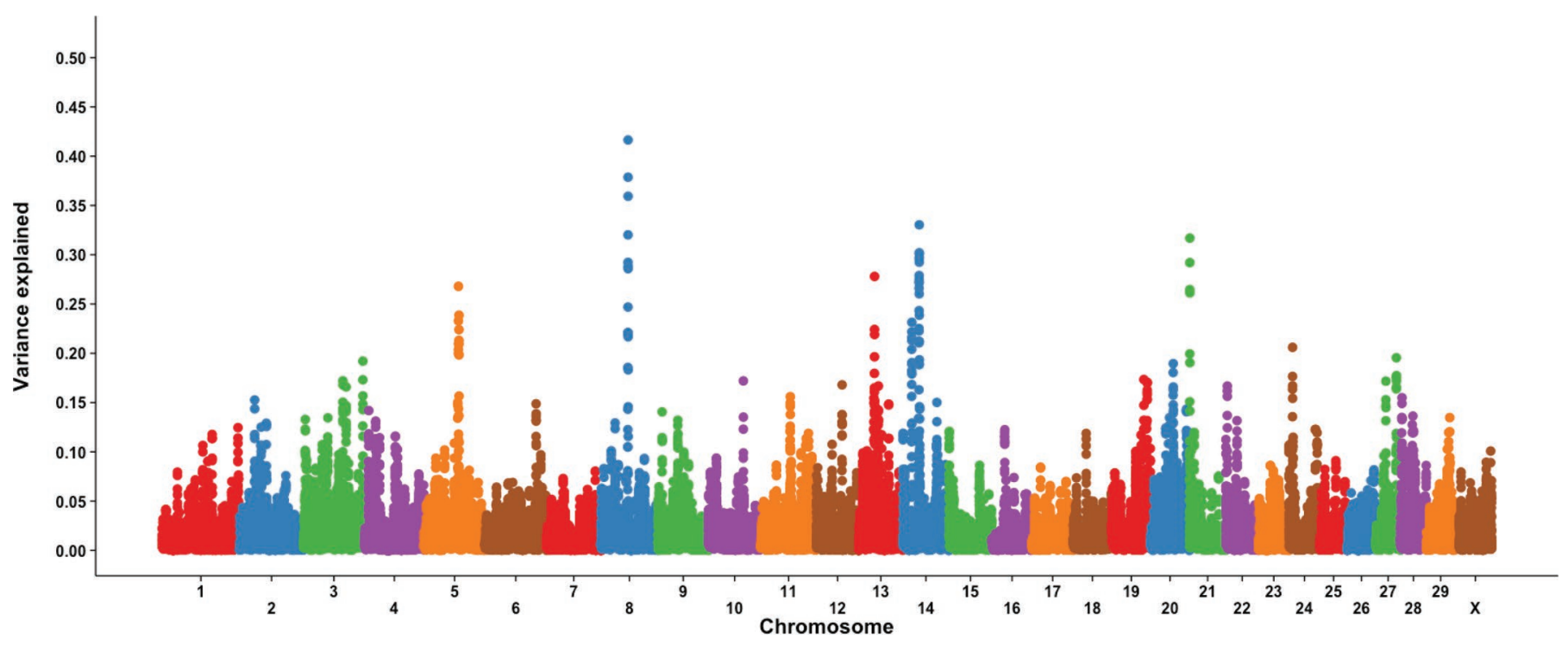

Figure 1. Proportion of SNP variance explained by 10-SNP windows associated with total structures recovered in the superovulation data set with logarithmic transformation. Color version available online.

Rank correlation between SNP effects associated with total structures recovered with the logarithmic transformation and the Anscombe transformation was 0.94. Among the top $10 \%$ of SNP effects, the rank correlation between SNP effects of the 2 transformations was 0.82 . For total number of structures, use of the Anscombe transformation resulted in the largest effect being located on BTA28 at $3,785,867$ bp (Supplemental Figure S2; https://doi.org/10.3168/jds.2016-11907). This SNP was also identified in the analysis with log-transformed data although it was not the largest effect in that case.

Much like the results of SNP effects, the window variance results were very similar between the 2 transformation methods for total structures recovered. The rank correlation of variance explained between the logtransformed data and the Anscombe-transformed data was 0.95 , indicating that both methods produce similar estimates of important genomic regions. Among the top $10 \%$ of windows explaining the most variance, there was some re-ranking between transformation methods as evidenced by a lower rank correlation of 0.84 , similar to what was found with the individual SNP effects. The region explaining the largest amount of variance in the Anscombe-transformed data was the same as in the log-transformed data (BTA8 at 55,663,248 bp; Figure 2 ). The same peaks explaining the largest proportions of variance were also identified with the Anscombetransformed data (BTA5, BTA13, BTA14, and BTA21; Figure 2).

Chromosomes with the largest SNP effects for number of good embryos collected (log-transformed) included BTA3 (5,227,519 bp), BTA5 (20,976,423 bp), BTA8 $(5,729,659 \mathrm{bp})$, BTA13 $(32,831,454 \mathrm{bp})$, and BTA14 $(27,600,296 \mathrm{bp})$. The largest effect was identified on BTA3 (Supplemental Figure S3; https://doi. org/10.3168/jds.2016-11907). The region explaining the largest proportion of variance for number of good embryos in the superovulation data was located on BTA14 (26,713,734 bp; Figure 3). The region on BTA8 that explained the most variance for total structures recovered was also identified as explaining a large proportion of variance for number of good embryos (Figure 3). Additional chromosomes with strong peaks explaining large proportions of variance included BTA5 $(75,599,879 \mathrm{bp})$, BTA10 (72,315,329 bp), and BTA13 $(34,887,980 \mathrm{bp})$.

Results for number of good embryos with the Anscombe transformation were very similar to those obtained from the log-transformed data. Rank correlations of SNP effects and variance explained between each transformation method were both equal to 0.96 . For the top 10\% of largest SNP effect and windows, the rank correlations between transformation methods were equal to 0.85 and 0.86 , respectively, indicating some reranking. The largest peak for SNP effects was the same for both data transformations (BTA3 at 5,227,519 bp). Additional chromosomes that had large SNP effects included BTA8 (5,729,659 bp), BTA13 $(32,831,454 \mathrm{bp})$, BTA19 $(3,858,863 \mathrm{bp})$, and BTA28 $(3,785,867 \mathrm{bp})$. The region explaining the largest proportion of variance was the same regardless of transformation as well (BTA14 at 26,713,734 bp). The same or very similar 


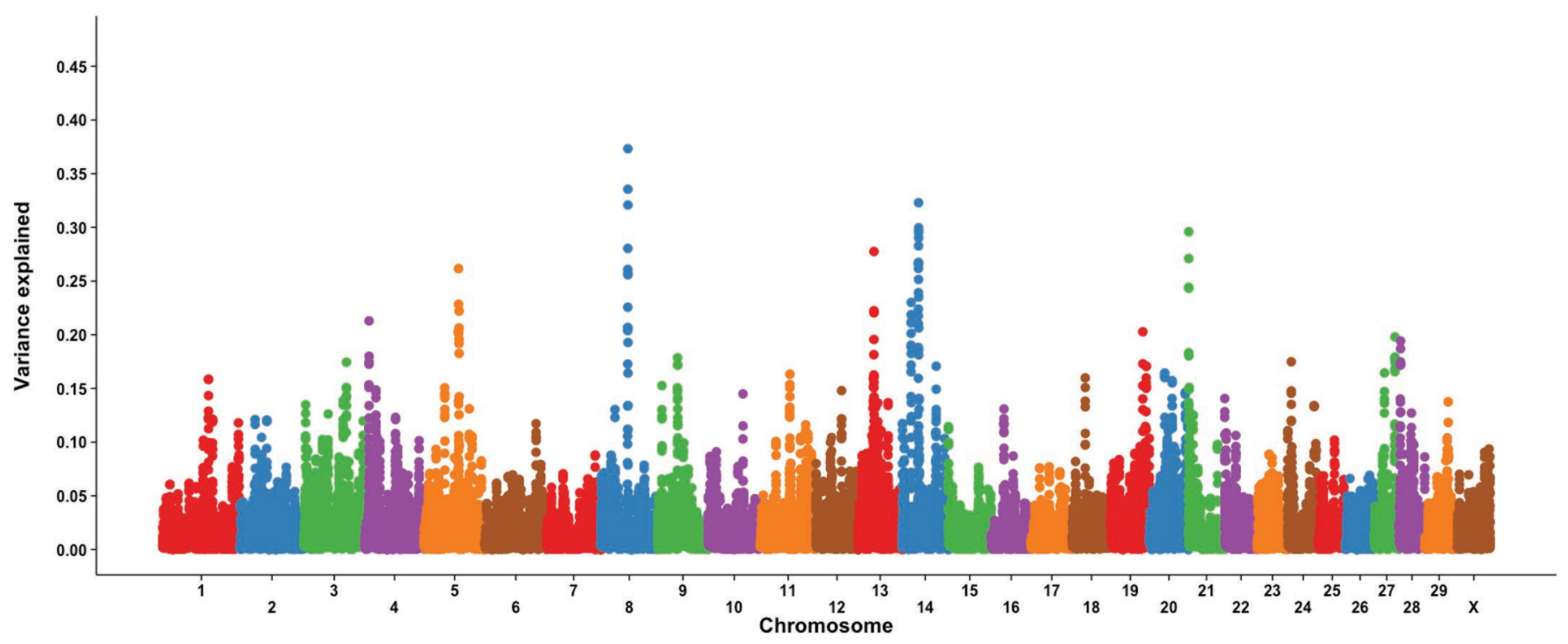

Figure 2. Proportion of SNP variance explained by 10-SNP windows associated with total structures recovered in the superovulation data set with Anscombe transformation. Color version available online.

regions were identified with the Anscombe transformation compared with the logarithmic transformation. These regions were located on BTA5 $(75,599,879 \mathrm{bp})$, BTA8 $(55,663,248 \mathrm{bp})$, BTA10 $(72,315,329 \mathrm{bp})$, and BTA13 $(34,851,781 \mathrm{bp})$. Manhattan plots of the results are included in Supplemental Figure S4 (https://doi. org/10.3168/jds.2016-11907) and Figure 4 for SNP effects and proportion of variance explained, respectively.

Regions of the genome associated with the traits of interest were further examined to identify putatively associated genes. The region on BTA8 at approximately $55.6 \mathrm{Mb}$ was identified by analyses of both total structures recovered and number of good embryos. Genes in this region of the genome included NPR2, TLE4, and TGFBR1. The NPR2 is involved in maintaining meiotic arrest of the oocyte (Liu et al., 2013). The TLE4 is a transcriptional repressor of canonical WNT signaling and has been implicated in differentiation of embryonic stem cells (Laing et al., 2015). More broadly, WNT signaling has been implicated in folliculogenesis and

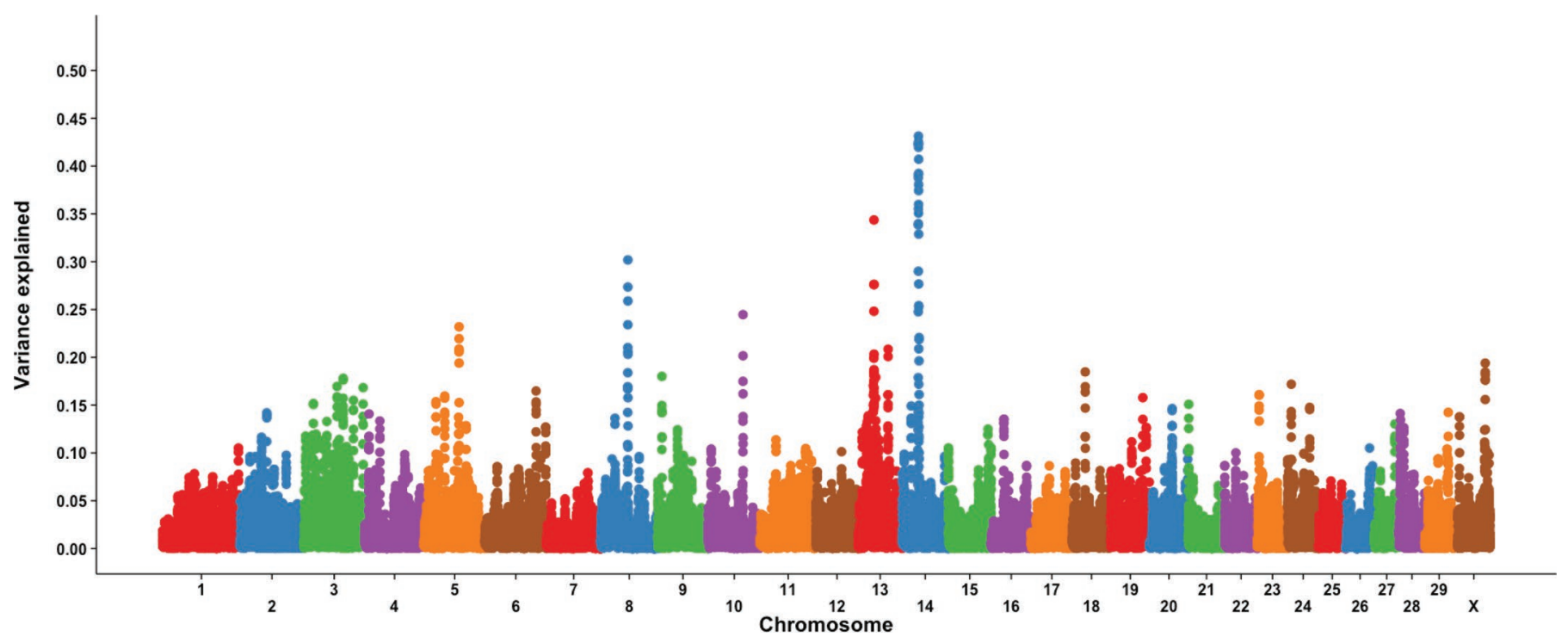

Figure 3. Proportion of SNP variance explained by 10-SNP windows associated with the number of good embryos in the superovulation data set with logarithmic transformation. Color version available online. 


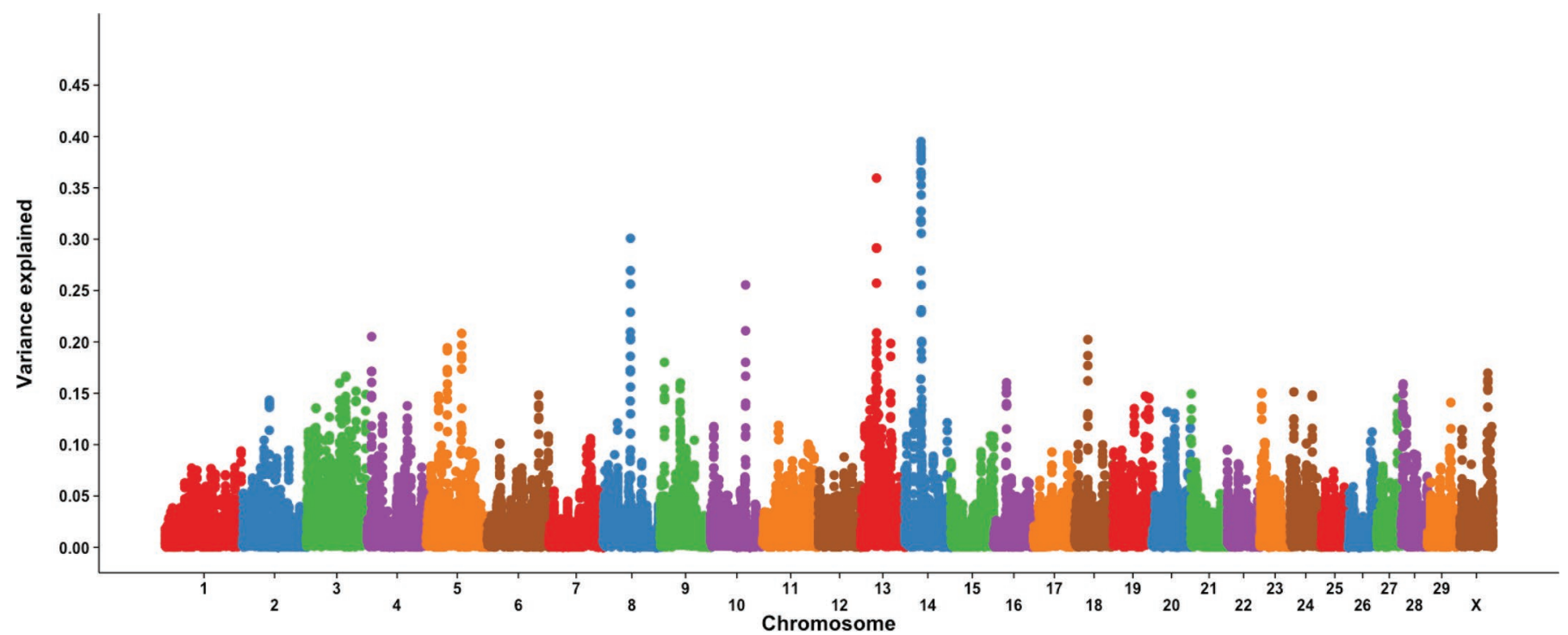

Figure 4. Proportion of SNP variance explained by 10-SNP windows associated with the number of good embryos in the superovulation data set with Anscombe transformation. Color version available online.

ovulation (Richards, 2007; Hernandez Gifford, 2015), and in cattle, it has been reported to be involved with embryo competence to establish pregnancy (Denicol et al., 2014). Additional genes associated with WNT pathways were identified on BTA14 at approximately 63.4 $\mathrm{Mbp}$ in the total structures recovered data set (Anscombe transformation). These genes included FZD6, which has been identified as having a potential role in dominant follicle selection (Gupta et al., 2014) and CTHRC1, which is involved in planar cell polarity and interacts with both $F z d$ and Wnt proteins (Yamamoto et al., 2008). The size of the pool of growing ovarian follicles is regulated by several proteins of the TGFB family of regulatory molecules (Pangas, 2012). Related to the TGFB family, a region on BTA16 identified in the analysis of number of good embryos (Anscombetransformed) included the PARP1 gene, which has been cited as being involved in the regulation of TGFBR1 and ovarian steroid signaling during embryo implantation (Joshi et al., 2014).

A region of BTA13 at approximately $35 \mathrm{Mb}$ was also identified in analyses of both total structures recovered and number of good embryos. This window included the following genes: KIAA1462, ZNF438, MTPAP, MUSK, MAP3K8, and SVIL. The MAP3K8 gene has been implicated in steroid secretion from cumulus cells (Huang et al., 2016) and corpus luteum (Liu et al., 2015). A second region was identified on BTA13 at approximately $32 \mathrm{Mb}$ in analyses of number of good embryos regardless of transformation method. This region included $C A C N B$ 2, which is involved in the release of FSH from the anterior pituitary gland and thought to modulate conception rates in cattle (Sugimoto et al., 2013). A region at approximately $32.1 \mathrm{Mbp}$ on BTA13 was previously associated with early embryonic survival in Holsteins (Huang et al., 2010).

A third region identified in all analyses was located on BTA14 at approximately $27 \mathrm{Mb}$. Genes in this region included TOX, NSMAF, SDCBP, CA8, RAB2A, and $C H D \%$. The $C H D$ \% gene is involved in the organization of chromatin and has associated Gene Ontology (GO) terms related to biological processes including in utero embryonic development (GO:0001701), embryonic hind limb morphogenesis (GO:0035116), and female genitalia development (GO:0030540). The $C H D$ 7 gene has also been implicated in the CHARGE syndrome, for which anomalies include retardation of growth and development and genital abnormalities, among other symptoms. Using the mouse as a model, researchers concluded that $\mathrm{CHD}^{7}$ may play an important role in regulating puberty and reproduction (Layman et al., 2011). A similar region on BTA14 was previously identified between 31.7 to $41.1 \mathrm{Mb}$ as affecting ovulation rate (Gonda et al., 2004).

A region on BTA10 at approximately $72 \mathrm{Mb}$ was found to explain 0.24 and $0.26 \%$ of variance in analyses of number of good embryos with log and Anscombe transformations, respectively. This region of the genome included the following genes: LRRC9, PCNXL4, DHRS7, SIX6, PPQC- $\alpha$, and LOC101902937. A similar region was previously identified on BTA10 at approximately $66.8 \mathrm{Mb}$ associated with early embryonic survival. A candidate gene of $B M P 4$ in this region was proposed by Li et al. (2012) to be associated with blas- 
tocyst development. It has been postulated that $B M P 4$ plays a role in regulating preimplantation embryo development (La Rosa et al., 2011).

Regions identified on BTA5 also aligned with previous research on ovulation rate. A large SNP effect identified in the analysis of number of good embryos (log-transformed) corresponded with a region at approximately $22 \mathrm{Mb}$ identified by Allan et al. (2009) associated with ovulation rate. A second region on BTA5 at approximately $75 \mathrm{Mb}$ explained 0.23 and $0.21 \%$ of variance for number of good embryos with log and Anscombe transformations, respectively. This corresponds to a region of BTA5 also previously associated with bovine ovulation rate (Kirkpatrick et al., 2000).

An additional gene of interest on BTA19, SEC14L1, was within regions identified with genome-wide association analyses associated with total number of structures recovered (regardless of transformation). This gene has previously been associated with both cow conception rate and SCS in Holstein cattle (Cochran et al., 2013). A marker having a large effect on heifer conception rate in US Holstein genetic evaluations (Council on Dairy Cattle Breeding, Bowie, MD) also aligned with a region on BTA6 at approximately $103 \mathrm{Mb}$ in the analysis of number of good embryos (log-transformed).

\section{In Vitro Fertilization Data Set}

Descriptive statistics of the untransformed data from the IVF data set can be found in Table 1. Least squares means calculated for each trait before transformation with respect to season and semen type (conventional, reverse-sorted female, and sorted frozen) showed no statistically significant differences, regardless of trait. For example, least squares means for number of oocytes collected were equal to $20.97 \pm 3.37$ for winter, $19.50 \pm$ 3.40 for spring, $17.23 \pm 3.38$ for summer, and $17.88 \pm$ 3.31 for fall. Least squares means for number of oocytes collected with respect to semen type were equal to 20.21 \pm 0.52 for normal semen, $21.90 \pm 0.64$ for reverse-sorted female semen, and $14.57 \pm 9.79$ for sorted frozen semen. Pedigree-based variance component estimates are given in Table 4. No variance components differed from zero for any of the traits in this data set. Heritability for proportion of high-quality embryos also did not significantly differ from zero $(0.041 \pm 0.096)$. We feel that this is most likely due to the small sample size, which resulted in large standard errors of estimates. Despite this, the heritability estimate for number of cleaved embryos was comparable to that reported by Merton et al. (2009) of $0.19 \pm 0.04$ for number of cleaved embryos at d 4. Merton et al. (2009) also reported a heritability of $0.16 \pm 0.04$ for number of transferrable embryos at d 7. This is higher than the heritability estimated in this study for number of transferrable embryos $(0.046$ \pm 0.098 and $0.031 \pm 0.096$ with logarithmic and Anscombe transformations, respectively). A heritability of $0.096 \pm 0.087$ also has been reported for the number of transferrable embryos produced in vivo (König et al., 2007). The estimates in this analysis were more similar to those of Tonhati et al. (1999) for number of transferrable embryos from superovulation procedures (0.03).

\section{Genomic Analyses}

Variance component estimates from genomic analyses of the IVF data set are included in Table 5. Genomic estimates of variance components were very similar to those obtained using only pedigree information. As in the pedigree-based analyses, estimates did not differ from zero due to large standard errors. Because of this, we did not estimate SNP effects for those variables.

\section{Embryo Transfer Data Set}

Descriptive statistics for the ET data set are included in Table 1. Mean pregnancy rate with respect to fixed effects were calculated with untransformed data with

Table 4. Pedigree-based estimates of variance components \pm SE for in vitro fertilization data set including total structures recovered, number of cleaved embryos, number of high-quality embryos, number of low-quality embryos, and number of transferrable embryos for each transformation, logarithmic (Ln) and Anscombe (Ans)

\begin{tabular}{|c|c|c|c|c|c|}
\hline Trait & Donor & $\begin{array}{l}\text { Permanent } \\
\text { environment }\end{array}$ & Residual & Heritability & Repeatability \\
\hline Total structures recovered - Ln & $0.051 \pm 0.04$ & $0.091 \pm 0.036$ & $0.105 \pm 0.007$ & $0.208 \pm 0.154$ & $0.575 \pm 0.045$ \\
\hline Total structures recovered - Ans & $0.803 \pm 0.673$ & $1.581 \pm 0.619$ & $2.163 \pm 0.138$ & $0.177 \pm 0.142$ & $0.524 \pm 0.047$ \\
\hline Number of cleaved embryos - Ln & $0.054 \pm 0.046$ & $0.084 \pm 0.041$ & $0.185 \pm 0.012$ & $0.168 \pm 0.137$ & $0.428 \pm 0.051$ \\
\hline Number of cleaved embryos - Ans & $0.641 \pm 0.584$ & $1.101 \pm 0.532$ & $2.609 \pm 0.166$ & $0.147 \pm 0.130$ & $0.400 \pm 0.050$ \\
\hline Number of high-quality embryos - Ln & $0.004 \pm 0.044$ & $0.139 \pm 0.050$ & $0.391 \pm 0.025$ & $0.007 \pm 0.082$ & $0.268 \pm 0.047$ \\
\hline Number of high-quality embryos - Ans & $0.006 \pm 0.172$ & $0.562 \pm 0.201$ & $1.539 \pm 0.098$ & $0.003 \pm 0.081$ & $0.270 \pm 0.047$ \\
\hline Number of low-quality embryos - Ln & $0.042 \pm 0.047$ & $0.077 \pm 0.043$ & $0.269 \pm 0.017$ & $0.108 \pm 0.120$ & $0.306 \pm 0.050$ \\
\hline Number of low-quality embryos - Ans & $0.210 \pm 0.272$ & $0.479 \pm 0.252$ & $1.546 \pm 0.098$ & $0.094 \pm 0.119$ & $0.308 \pm 0.049$ \\
\hline Number of transferrable embryos - Ln & $0.024 \pm 0.050$ & $0.121 \pm 0.051$ & $0.368 \pm 0.023$ & $0.046 \pm 0.098$ & $0.281 \pm 0.048$ \\
\hline Number of transferrable embryos - Ans & $0.095 \pm 0.295$ & $0.790 \pm 0.310$ & $2.167 \pm 0.138$ & $0.031 \pm 0.096$ & $0.290 \pm 0.047$ \\
\hline
\end{tabular}


Table 5. Genomic estimates of variance components \pm SE for in vitro fertilization data set including total structures recovered, number of cleaved embryos, number of high-quality embryos, number of low-quality embryos, and number of transferrable embryos for each transformation, logarithmic (Ln) and Anscombe (Ans)

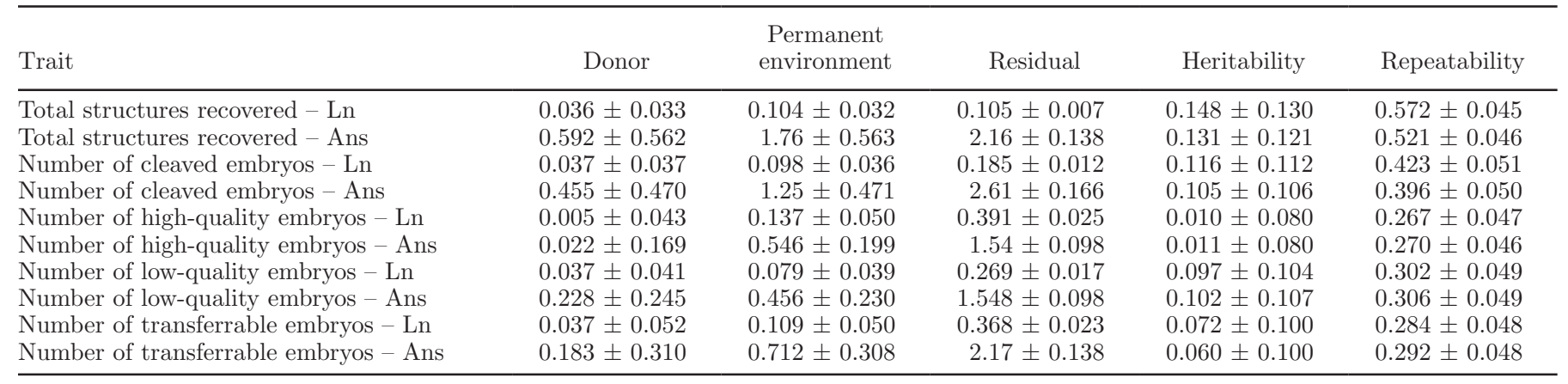

results listed in Table 6. Based on these results, fresh embryos had a higher rate of ET success compared with IVF or frozen. As expected, embryos with quality level 1 had the highest ET success rate, whereas embryos with quality level 3 had the lowest ET success rate. Sig-

Table 6. Mean, SE, and $95 \%$ confidence limit of mean pregnancy success $^{1}$ with respect to embryo type, semen type, embryo quality, embryo stage, and season from the untransformed embryo transfer data set

\begin{tabular}{|c|c|c|c|}
\hline Effect level & Mean & SE & $\begin{array}{l}\text { Confidence } \\
\text { limit }\end{array}$ \\
\hline \multicolumn{4}{|l|}{ Embryo type } \\
\hline Superovulation-fresh & 0.483 & 0.015 & $(0.46,0.51)$ \\
\hline Superovulation-frozen & 0.364 & 0.011 & $(0.34,0.39)$ \\
\hline IVF-fresh & 0.389 & 0.005 & $(0.38,0.40)$ \\
\hline IVF-frozen & 0.341 & 0.019 & $(0.30,0.38)$ \\
\hline \multicolumn{4}{|l|}{ Embryo quality $^{2}$} \\
\hline 1 & 0.421 & 0.005 & $(0.41,0.43)$ \\
\hline 2 & 0.324 & 0.010 & $(0.30,0.34)$ \\
\hline 3 & 0.244 & 0.015 & $(0.21,0.27)$ \\
\hline \multicolumn{4}{|l|}{ Embryo stage ${ }^{3}$} \\
\hline 3 & 0.210 & 0.096 & $(0.01,0.41)$ \\
\hline 4 & 0.369 & 0.009 & $(0.35,0.39)$ \\
\hline 5 & 0.341 & 0.010 & $(0.32,0.36)$ \\
\hline 6 & 0.381 & 0.009 & $(0.37,0.40)$ \\
\hline 7 & 0.453 & 0.008 & $(0.44,0.47)$ \\
\hline 8 & 0.338 & 0.054 & $(0.23,0.45)$ \\
\hline 9 & 0 & $\mathrm{NA}^{4}$ & NA \\
\hline \multicolumn{4}{|l|}{ Semen type } \\
\hline Conventional & 0.399 & 0.006 & $(0.39,0.41)$ \\
\hline Reverse-sorted female & 0.376 & 0.007 & $(0.36,0.39)$ \\
\hline Sorted frozen & 0 & $\mathrm{NA}^{4}$ & NA \\
\hline \multicolumn{4}{|l|}{ Season } \\
\hline Winter & 0.397 & 0.008 & $(0.38,0.41)$ \\
\hline Spring & 0.401 & 0.008 & $(0.39,0.42)$ \\
\hline Summer & 0.393 & 0.011 & $(0.37,0.41)$ \\
\hline Fall & 0.373 & 0.009 & $(0.36,0.39)$ \\
\hline
\end{tabular}

${ }^{1}$ Pregnancy diagnosis was by rectal palpation of the reproductive tract at approximately $41 \mathrm{~d}$ of gestation.

${ }^{2}$ Embryo quality levels: $1=$ good or excellent; $2=$ fair; $3=$ poor.

${ }^{3}$ Embryo stage levels: $3=$ early morula; $4=$ compact morula; $5=$ early blastocyst; $6=$ blastocyst; $7=$ expanded blastocyst; $8=$ hatching blastocyst; $9=$ hatched blastocyst.

${ }^{4}$ Effect level had few records, all with the same outcome (no pregnancy). nificant differences could not be identified among levels of semen type or season, indicating that these variables did not significantly affect success of ET. Variance components estimates using the additive relationship matrix are included in Table 7. Heritability of pregnancy success for the recipient was equal to 0.028 (SD $=0.013)$, which is lower than that reported by König et al. (2007), but falls within the range of heritability estimates reported for similar traits such as nonreturn rate and conception rate (e.g., Weigel and Rekaya, 2000; VanRaden et al., 2004; Jamrozik et al., 2005). Permanent environment of the recipient accounted for a larger proportion of variance compared with the additive effect, resulting in repeatability equal to 0.064 (SD $=0.020$ ) for the recipient's ability to become pregnant following ET. Heritability of pregnancy success as it relates to an embryo resulting in a viable pregnancy from ET was small, equal to $0.024(\mathrm{SD}=0.011)$. This result was comparable to that reported by König et al. (2007) in German Holstein cows. It was also similar to the genetic effect of donor and sire effect on ET success $(<0.01)$ when these effects were estimated separately (König et al., 2007). Low heritability of the embryo's influence on pregnancy success of the recipient may be at least partially explained by pre-selection of higher quality embryos for transfer. A negative genetic correlation equal to $-0.77(\mathrm{SD}=0.32)$ was estimated between the embryo and recipient (Table 7). Previous research has also reported a negative covariance between embryo and recipient effects (König et al., 2007). Because heritability estimates were not found to be statistically greater than zero, we did not proceed with genomic analyses for the ET data set.

Heritabilities estimated for traits in the superovulation and IVF data sets (i.e., those related to superovulatory response) were in many cases higher than heritability of common fertility traits such as pregnancy rate or calving interval, which generally have low heritabilities of less than $5 \%$. It has been proposed 
Table 7. Pedigree-based estimates of variance components and standard deviation for embryo transfer data set

\begin{tabular}{lrc}
\hline Item & Estimate & $\mathrm{SD}$ \\
\hline Embryo & 0.025 & 0.011 \\
Embryo-Recipient covariance & -0.021 & 0.012 \\
Embryo-Recipient correlation & -0.772 & 0.321 \\
Recipient & 0.029 & 0.013 \\
Permanent environment of recipient & 0.039 & 0.021 \\
Residual & 1.004 & 0.018 \\
Heritability of embryo & 0.024 & 0.011 \\
Heritability of recipient & 0.028 & 0.013 \\
Repeatability of recipient & 0.064 & 0.020 \\
\hline
\end{tabular}

that this discrepancy is because response to superovulatory treatment is a less complex trait (Eriksson et al., 2007). It also indicates that genetic improvement of animal response to superovulatory treatments may be achieved more easily compared with overall fertility. Selection for traits related to superovulatory response would be beneficial for producers using reproductive technologies. Estimates of heritability for traits related to IVF were also higher than traditional fertility traits, but additional data collection would be necessary to confirm these results with a smaller margin of error. Given the genetic component of the traits, it would be possible to select animals most likely to respond favorably to superovulation and IVF procedures. Conversely, heritabilities related to ET were lowly heritable, more similar to traditional fertility traits. This likely reflects the numerous factors affecting pregnancy success such as effects of the donor and sire, embryo vitality, and recipient.

The transformation method should be investigated with any data set to ensure that the transformed data results in a more normal distribution. In our data, results were not affected by the transformation method. Ratio values (i.e., heritability and repeatability) were very similar between the 2 transformations that were applied. Given that logarithmic transformations are more commonly used, this may be the best choice for consistency across studies in the future.

Similarity between GWAS results for total structures recovered and number of good embryos is supported by the high genetic correlation between the traits. Several regions were similar to those identified in other studies investigating fertility traits, which may be indicative of an underlying effect on fertility. Putatively associated genes were identified in these regions; however, further research is needed to validate these regions. One drawback of the data presented herein is that it was collected from a single herd. Collection of more data, including data from additional farms, will help to confirm results presented herein. The number of herds that collect this type of data in the United States is likely small, but may grow with increasing interest in reproductive technologies.

\section{CONCLUSIONS}

Results of this study indicate that selection for traits related to reproductive technologies is possible. Estimated heritabilities were low to moderate. As interest in these technologies increases, genetic selection will allow producers to identify cows more likely to respond favorably to procedures such as superovulation and in vitro fertilization. Regions of the genome associated with superovulation traits identified genes of interest to be further investigated and validated.

\section{ACKNOWLEDGMENTS}

Financial support for this study was provided by Agriculture and Food Research Initiative Grant 201368004-20365, "Improving Fertility of Dairy Cattle Using Translational Genomics," from the National Institute of Food and Agriculture and a grant from the Southeast Milk Checkoff Program. Cole and Null were supported by appropriated project 1265-31000-096-00, "Improving Genetic Predictions in Dairy Animals Using Phenotypic and Genomic Information," of the Agricultural Research Service of the United States Department of Agriculture. The authors thank North Florida Holsteins (Bell, FL), Christine Meyer and Ashlee Johnson in particular, for providing access to data and other assistance. Mention of trade names or commercial products in this article is solely for the purpose of providing specific information and does not imply recommendation or endorsement by the US Department of Agriculture. The USDA is an equal opportunity provider and employer.

\section{REFERENCES}

Aguilar, I., I. Misztal, A. Legarra, and S. Tsuruta. 2011. Efficient computation of the genomic relationship matrix and other matrices used in single-step evaluation. J. Anim. Breed. Genet. 128:422428. https://doi.org/10.1111/j.1439-0388.2010.00912.x.

Aguilar, I., I. Misztal, S. Tsuruta, A. Legarra, and H. Wang. 2014 PREGSF90 - POSTGSF90: Computational tools for the implementation of single-step genomic selection and genome-wide association with ungenotyped individuals in BLUPF90 programs. In Proc. 10th World Congr. Genet. Appl. Livest. Prod. Vancouver, Canada. American Society of Animal Science, Champaign, IL.

Allan, M. F., L. A. Kuehn, R. A. Cushman, W. M. Snelling, S. E. Echternkamp, and R. M. Thallman. 2009. Confirmation of quantitative trait loci using a low-density single nucleotide polymorphism map for twinning and ovulation rate on bovine chromosome 5. J. Anim. Sci. 87:46-56. https://doi.org/10.2527/jas.2008-0959.

Anscombe, F. J. 1948. The transformation of Poisson, binomial and negative-binomial data. Biometrika 35:246-254. https://doi. org $/ 10.2307 / 2332343$.

Cochran, S. D., J. B. Cole, D. J. Null, and P. J. Hansen. 2013. Discovery of single nucleotide polymorphisms in candidate genes associ- 
ated with fertility and production traits in Holstein cattle. BMC Genet. 14:49. https://doi.org/10.1186/1471-2156-14-49.

Colleau, J. J. 1991. Using embryo sexing within closed mixed multiple ovulation and embryo transfer schemes for selection on dairy cattle. J. Dairy Sci. 74:3973-3984. https://doi.org/10.3168/jds. S0022-0302(91)78592-5.

Council on Dairy Cattle Breeding. 2014. Description of National Genetic Evaluation Systems: Production (milk, fat, protein). Accessed Oct. 21, 2016. https://www.cdcb.us/reference/Form_GE_ Yield_1412.pdf.

Denicol, A. C., J. Block, D. E. Kelley, K. G. Pohler, K. B. Dobbs, C J. Mortensen, M. S. Ortega, and P. J. Hansen. 2014. The WNT signaling antagonist Dickkopf-1 directs lineage commitment and promotes survival of the preimplantation embryo. FASEB J. 28:3975-3986. https://doi.org/10.1096/fj.14-253112.

Elsik, C. G., D. R. Unni, C. M. Diesh, A. Tayal, M. L. Emery, H. N. Nguyen, and D. E. Hagen. 2016. Bovine Genome Database: New tools for gleaning function from the Bos taurus genome. Nucleic Acids Res. 44:D834-D839. https://doi.org/10.1093/nar/gkv1077.

Eriksson, S., M. Häggström, and H. Stålhammar. 2007. Genetic parameters for superovulatory response in Swedish Red Cattle and Swedish Holstein heifers. Pages 1-6 in 58th Annu. Meet. Eur. Assoc. Anim. Prod., Dublin, Ireland. Wageningen Academic Publishers, Wageningen, the Netherlands.

Ferraz, P. A., C. Burnley, J. Karanja, A. Viera-Neto, J. E. P. Santos, R. C. Chebel, and K. N. Galvão. 2016. Factors affecting the success of a large embryo transfer program in Holstein cattle in a commercial herd in the southeast region of the United States. Theriogenology 86:1834-1841.

Finney, D. J. 1948. Transformation of frequency distributions. Nature 162:898.

Gonda, M. G., J. A. Arias, G. E. Shook, and B. W. Kirkpatrick. 2004. Identification of an ovulation rate QTL in cattle on BTA14 using selective DNA pooling and interval mapping. Anim. Genet. 35:298-304. https://doi.org/10.1111/j.1365-2052.2004.01162.x.

Gupta, P. S. P., J. K. Folger, S. K. Rajput, L. Lv, J. Yao, J. J. Ireland, and G. W. Smith. 2014. Regulation and regulatory role of WNT signaling in potentiating FSH action during bovine dominant follicle selection. PLoS One 9:e100201. https://doi.org/10.1371/ journal.pone.0100201.

Hasler, J. F. 2014. Forty years of embryo transfer in cattle: A review focusing on the journal Theriogenology, the growth of the industry in North America, and personal reminisces. Theriogenology 81:152-169.

Hernandez Gifford, J. A. 2015. The role of WNT signaling in adult ovarian folliculogenesis. Reproduction 150:R137-R148. https:// doi.org/10.1530/REP-14-0685.

Hu, Z. L., C. A. Park, X. L. Wu, and J. M. Reecy. 2013. Animal QTLdb: An improved database tool for livestock animal QTL/association data dissemination in the post-genome era. Nucleic Acids Res. 41:871-879. https://doi.org/10.1093/nar/gks1150.

Huang, W., B. W. Kirkpatrick, G. J. M. Rosa, and H. Khatib. 2010. A genome-wide association study using selective DNA pooling identifies candidate markers for fertility in Holstein cattle. Anim. Genet. 41:570-578. https://doi.org/10.1111/j.1365-2052.2010.02046.x.

Huang, X., C. Liu, C. Hao, Q. Tang, R. Liu, S. Lin, L. Zhang, and W. Yan. 2016. Identification of altered microRNAs and mRNAs in the cumulus cells of PCOS patients: miRNA-509-3p promotes oestradiol secretion by targeting MAP3K8. Reproduction 151:643-655. https://doi.org/10.1530/REP-16-0071.

Jamrozik, J., J. Fatehi, G. J. Kistemaker, and L. R. Schaeffer. 2005. Estimates of genetic parameters for Canadian Holstein female reproduction traits. J. Dairy Sci. 88:2199-2208. https://doi. org/10.3168/jds.S0022-0302(05)72895-2.

Jaton, C., A. Koeck, F. Miglior, C. A. Price, M. Sargolzaei, and F. S. Schenkel. 2016. Genetic analysis of superovulatory response of Holstein cows in Canada. J. Dairy Sci. 99:3612-3623. https://doi. org $/ 10.3168 /$ jds.2015-10349.

Joshi, A., S. Mahfooz, V. K. Maurya, V. Kumar, C. S. Basanna, G. Kaur, K. Hanif, and R. K. Jha. 2014. PARP1 during embryo im- plantation and its upregulation by oestradiol in mice. Reproduction 147:765-780. https://doi.org/10.1530/REP-13-0588.

Kirkpatrick, B. W., B. M. Byla, and K. E. Gregory. 2000. Mapping quantitative trait loci for bovine ovulation rate. Mamm. Genome 11:136-139. https://doi.org/10.1007/s003350010026.

Klei, B., and S. Tsuruta. 2008. Approximate variance for heritability estimates. Accessed Jun. 14, 2016. http://nce.ads.uga. edu/ $\sim$ shogo $/$ html/research/AI_SE.pdf.

König, S., F. Bosselmann, U. U. von Borstel, and H. Simianer. 2007. Genetic analysis of traits affecting the success of embryo transfer in dairy cattle. J. Dairy Sci. 90:3945-3954. https://doi.org/10.3168/ jds.2007-0089.

La Rosa, I., L. S. A. Camargo, M. M. Pereira, R. Fernandez-Martin, D. A. Paz, and D. F. Salamone. 2011. Effects of bone morphogenic protein 4 (BMP4) and its inhibitor, Noggin, on in vitro maturation and culture of bovine preimplantation embryos. Reprod. Biol. Endocrinol. 9:18 https://doi.org/10.1186/1477-7827-9-18

Laing, A. F., S. Lowell, and J. M. Brickman. 2015. Gro/TLE enables embryonic stem cell differentiation by repressing pluripotent gene expression. Dev. Biol. 397:56-66. https://doi.org/10.1016/j. ydbio.2014.10.007.

Layman, W. S., E. A. Hurd, and D. M. Martin. 2011. Reproductive dysfunction and decreased GnRH neurogenesis in a mouse model of CHARGE syndrome. Hum. Mol. Genet. 20:3138-3150. https:// doi.org $/ 10.1093 / \mathrm{hmg} / \mathrm{ddr} 216$.

Li, G., K. Khateeb, E. Schaeffer, B. Zhang, and H. Khatib. 2012 Genes of the transforming growth factor-beta signalling pathway are associated with pre-implantation embryonic development in cattle. J. Dairy Res. 79:310-317. https://doi.org/10.1017/ S0022029912000210.

Liu, L., N. Kong, G. Xia, and M. Zhang. 2013. Molecular control of oocyte meiotic arrest and resumption. Reprod. Fertil. Dev. 25:463471. https://doi.org/10.1071/RD12310.

Liu, Y., Y. Li, D. Zhang, J. Liu, K. Gou, and S. Cui. 2015. Mitogen-activated protein kinase 8 (MAP3K8) mediates the signaling pathway of estradiol stimulating progesterone production through G protein-coupled receptor 30 (GPR30) in mouse corpus luteum. Mol. Endocrinol. 29:703-715. https://doi.org/10.1210/me.20151009

Loi, P., P. Toschi, F. Zacchini, G. Ptak, P. A. Scapolo, E. Capra, A. Stella, P. A. Marsan, and J. L. Williams. 2016. Synergies between assisted reproduction technologies and functional genomics. Genet. Sel. Evol. 48:53 https://doi.org/10.1186/s12711-016-0231-z.

Lourenco, D. A. L., I. Misztal, S. Tsuruta, I. Aguilar, T. J. Lawlor, S. Forni, and J. I. Weller. 2014. Are evaluations on young genotyped animals benefiting from the past generations? J. Dairy Sci. 97:3930-3942. https://doi.org/10.3168/jds.2013-7769.

Machado, S. A., H. D. Reichenbach, M. Weppert, E. Wolf, and P. B. D. Gonçalves. 2006. The variability of ovum pick-up response and in vitro embryo production from monozygotic twin cows. Theriogenology 65:573-583. https://doi.org/10.1016/j. theriogenology.2005.04.032.

Merton, J. S., B. Ask, D. C. Onkundi, E. Mullaart, B. Colenbrander and M. Nielen. 2009. Genetic parameters for oocyte number and embryo production within a bovine ovum pick-up-in vitro production embryo-production program. Theriogenology 72:885-893. https://doi.org/10.1016/j.theriogenology.2009.06.003

Meuwissen, T. H. E., B. J. Hayes, and M. E. Goddard. 2001. Prediction of total genetic value using genome-wide dense marker maps. Genetics 157:1819-1829

Misztal, I., S. Tsuruta, T. Strabel, B. Auvray, T. Druet, and D. H. Lee. 2002. BLUPF90 and related programs (BGF90). Pages 1-2 in Proc. 7th World Congr. Genet. Appl. Livest. Prod., Montpellier, France. INRA (Institut National de la Recherche Agronomique), Cedex, France.

Morotti, F., B. V. Sanches, J. H. F. Pontes, A. C. Basso, E. R. Siqueira, L. A. Lisboa, and M. M. Seneda. 2014. Pregnancy rate and birth rate of calves from a large-scale IVF program using reversesorted semen in Bos indicus, Bos indicus-taurus, and Bos taurus cattle. Theriogenology 81:696-701. https://doi.org/10.1016/j. theriogenology.2013.12.002. 
Nicholas, F. W., and C. Smith. 1983. Increased rates of genetic change in dairy cattle by embryo transfer and splitting. Anim. Sci. 36:341353.

Pangas, S. A. 2012. Regulation of the ovarian reserve by members of the transforming growth factor beta family. Mol. Reprod. Dev. 79:666-679. https://doi.org/10.1002/mrd.22076.

Perry, G. 2015. 2014 statistics of embryo collection and transfer in domestic animals. Embryo Transfer Newsletter 33:9-18.

Richards, J. S. 2007. Genetics of ovulation. Semin. Reprod. Med. $25: 235-242$.

Robertson, I., and R. E. Nelson. 1998. Certification and identification of the embryo. Pages 103-116 in Manual of the International Embryo Transfer Society. D. A. Stringfellow and S. E. Seidel, ed. International Embryo Transfer Society, Champaign, IL.

Ruane, J., and R. Thompson. 1991. Comparison of simulated and theoretical results in adult MOET nucleus schemes for dairy cattle. Livest. Prod. Sci. 28:1-20. https://doi.org/10.1016/03016226(91)90051-Q.

Sokal, R. R., and F. J. Rohlf. 1995. Biometry: The Principles and Practice of Statistics in Biological Research. 3rd ed. WH Freeman, New York, NY.

Sugimoto, M., S. Sasaki, Y. Gotoh, Y. Nakamura, Y. Aoyagi, T. Kawahara, and Y. Sugimoto. 2013. Genetic variants related to gap junctions and hormone secretion influence conception rates in cows. Proc. Natl. Acad. Sci. USA 110:19495-19500. https://doi. org/10.1073/pnas.1309307110.

Thomasen, J. R.. A. Willam, C. Egger-Danner, and A. C. Sørensen. 2016. Reproductive technologies combine well with genomic selection in dairy breeding programs. J. Dairy Sci. 99:1331-1340. https://doi.org/10.3168/jds.2015-9437.

Tonhati, H., R. B. Lobo, and H. N. Oliveira. 1999. Repeatability and heritability of response to superovulation in Holstein cows. Theriogenology 51:1151-1156.
Tsuruta, S., and I. Misztal. 2006. THRGIBBS1F90 for estimation of variance components with threshold linear models. Pages 27-31 in Proc. 8th World Congr. Genet. Appl. Livest. Prod., Belo Horizonte, Brazil.

VanRaden, P. M., and J. B. Cole. 2014. Net merit as a measure of lifetime profit: 2014 revision. Beltsville, MD. Accessed Jun. 1, 2016. http://aipl.arsusda.gov/reference/nmcalc-2014.htm.

VanRaden, P. M., A. H. Sanders, M. E. Tooker, R. H. Miller, H. D. Norman, M. T. Kuhn, and G. R. Wiggans. 2004. Development of a national genetic evaluation for cow fertility. J. Dairy Sci. 87:22852292. https://doi.org/10.3168/jds.S0022-0302(04)70049-1.

Weigel, K. A., and R. Rekaya. 2000. Genetic parameters for reproductive traits of Holstein cattle in California and Minnesota. J. Dairy Sci. 83:1072-1080. https://doi.org/10.3168/jds.S00220302(00)74971-X.

Wiggans, G. R., T. A. Cooper, D. J. Null, and P. M. Vanraden. 2014. Increasing the number of single nucleotide polymorphisms used in genomic evaluations of dairy cattle. Pages $1-3$ in Proc. 10th World Congr. Genet. Appl. Livest. Prod., Vancouver, Canada. American Society of Animal Science, Champaign, IL.

Yamamoto, S., O. Nishimura, K. Misaki, M. Nishita, Y. Minami, S. Yonemura, H. Tarui, and H. Sasaki. 2008. Cthrc1 selectively activates the planar cell polarity pathway of Wnt signaling by stabilizing the Wnt-receptor complex. Dev. Cell 15:23-36. https://doi. org/10.1016/j.devcel.2008.05.007.

Yang, H., and G. Su. 2016. Impact of phenotypic information of previous generations and depth of pedigree on estimates of genetic parameters and breeding values. Livest. Sci. 187:61-67. https:// doi.org/10.1016/j.livsci.2016.03.001. 